\title{
Validation of the Youth Psychopathic Traits Inventory and Youth Psychopathic Traits Inventory - Short Version Among Incarcerated Juvenile Delinquents
}

\author{
Pedro Pechorro $^{1} \cdot$ Henrik Andershed ${ }^{2} \cdot$ James V. Ray $^{3} \cdot$ João Maroco $^{4}$. \\ Rui Abrunhosa Gonçalves ${ }^{1}$
}

(C) Springer Science+Business Media New York 2015

\begin{abstract}
The aim of the present study was to examine the psychometric properties of the Youth Psychopathic Traits Inventory (YPI) and of the Youth Psychopathic Traits Inventory - Short version (YPI-S) among Portuguese juvenile delinquents within a forensic sample of 221 incarcerated males (ages 13-20 years). Confirmatory Factor Analysis supported the three-factor structure of the YPI and YPI-S, and the reliability of both instruments was good for the majority of subscales and factors. The YPI and YPI-S and their subscales showed good criterion, external, and divergent validity. That is, positive associations were found with a number of external criteria including Conduct Disorder, crime seriousness, and violent crimes. Total and subscale scores on both YPI versions were positively related to the Antisocial Process Screening Device, the Inventory of Callous-Unemotional Traits, and
\end{abstract}

Pedro Pechorro

ppechorro@gmail.com

Henrik Andershed

henrik.andershed@oru.se

James V. Ray

james.ray@utsa.edu

João Maroco

jpmaroco@ispa.pt

Rui Abrunhosa Gonçalves

rabrunhosa@psi.uminho.pt

1 School of Psychology, University of Minho, Campus de Gualtar, 4710-057 Braga, Portugal

2 School of Law, Psychology and Social Work, Örebro University, 70182 Örebro, Sweden

3 Department of Criminal Justice, University of Texas at San Antonio, 501 W Cesar E. Chavez, Blvd., San Antonio, TX 78207, USA

4 ISPA - Instituto Universitário, Rua Jardim do Tabaco, 34, 1149-041 Lisbon, Portugal the Child and Adolescent Taxon Scale. Finally, both the YPI and YPI-S were mostly unrelated to the Social Anxiety Scale for Adolescents. Overall, the YPI-S presented less problems with reliability, but weaker relations to external correlates. These findings justify the use of the YPI and the YPI-S among incarcerated youths.

Keywords Assessment · Youth Psychopathic Traits Inventory (YPI) - Youth Psychopathic Traits Inventory - Short version (YPI-S) · Juvenile delinquency $\cdot$ Validation

Psychopathy has become important in the identification of a more serious and persistent subgroup of antisocial youth. Juveniles with high psychopathic traits begin their criminal activities earlier in life, commit more serious crimes, have higher predisposition to use weapons, and their victims sustain greater injury (Frick et al. 2003; Murrie et al. 2004; Pechorro et al. 2014a; Salekin et al. 2004; Vitacco et al. 2007). Psychopathic traits in offenders are associated with more institutional violence (Brandt et al. 1997), higher rates of recidivism, and a shorter time between release and re-offense compared to offenders without these traits (Gretton et al. 2004; Hildebrand et al. 2004; Leistico et al. 2008; Rice and Harris 2013).

In turn, juvenile psychopathy has gained importance in forensic theory and practice (Häkkänen-Nyholm and Nyholm 2012; Salekin and Lynam 2010; Vitacco and Salekin 2013). Researchers, borrowing from the established nomological network of adult psychopathy, have modified assessment instruments to make them developmentally appropriate for use with youth (e.g., Forth et al. 2003; Frick and Hare 2001). Such efforts provide the possibility of a more vast understanding of the etiology of the disorder and of early 
identification and treatment (Lindberg 2012; Pardini and Byrd 2013; Salekin 2010).

Clinical assessments of psychopathy such as the Psychopathy Checklist: Youth Version (PCL:YV; Forth et al. 2003) are valid and useful measures of psychopathy, however, they tend to be time-consuming, expensive, and difficult to use (e.g., require intensive training). Additionally, such measures are less applicable among community samples because they require access to institutional file information in order to calculate a total score (Colins et al. 2012). Another suggested limitation of such measures has to do with tautology. That is, antisocial behavior can be considered a consequence, not a core feature, of the psychopathy construct (e.g., Weizmann-Henelius et al. 2010). Alternatively, parent, teacher, and self-report measures, such as the Antisocial Process Screening Device (APSD; Frick and Hare 2001), have proven useful for circumventing such issues associated with clinical measures and avoid the inclusion of items reflecting antisocial behavior. However, the APSD itself has some limitations (e.g., low reliability, response bias; Andershed et al. 2002b; Falkenbach et al. 2003).

The Youth Psychopathic traits Inventory (YPI; Andershed et al. 2002a), on the other hand, addresses some of the limitations of other self-report psychopathy measures, in addition to those of clinical measures (e.g., Kotler and McMahon 2005; Vaughn and Howard 2005). The YPI was modeled after Cleckley's (1976) theory and Hare's (1991, 2003) operationalization of psychopathy and was intended to capture the core personality features of psychopathy: interpersonal (e.g., glib, manipulative) and affective (e.g., callous, shallow affect), and behavioral (e.g., fearless, impulsive) components. However, the authors intentionally avoided items that overlapped with behavioral outcomes of these traits (e.g., criminal behavior; Andershed et al. 2002a, b). The YPI is comprised of 10 subscales that combine into a three-factor structure consistent with recent psychopathy theoretical models (e.g., Cooke and Michie 2001). Each subscale consists of 5 items enabling trait-level assessment and enhancing its reliability. Items were also intended to capture feelings and opinions as competences or neutral traits, rather than obvious deficiencies in order to avoid socially desirable responding.

The psychometric properties of the YPI have been examined among community, clinical, and forensic samples (Andershed et al. 2002a, b, 2007; Cauffman et al. 2009; Dolan and Rennie 2007; Poythress et al. 2006; Salekin et al. 2010; Skeem and Cauffman 2003). Exploratory and confirmatory factor analyses have shown that the YPI subscales form the expected three-factor structure conceptualization of the psychopathy construct (i.e., Grandiose-Manipulative, Callous-Unemotional, and Impulsive-Irresponsible dimensions; Andershed et al. 2002a, b, 2007; Van Baardewijk et al. 2010). The internal consistencies measured by Cronbach's alpha of the three YPI dimensions and the total scores have generally been good to very good: the YPI total ranging from 0.87 to 0.92 , the Grandiose-Manipulative dimension from 0.82 to 0.90 , the Callous-Unemotional dimension from 0.74 to 0.81 , and the Impulsive-Irresponsible dimension from 0.68 to 0.85 (Andershed et al. 2002a, b, 2007; Larsson et al. 2006; Skeem and Cauffman 2003).

The YPI has demonstrated that it can identify a severe and aggressive subgroup of antisocial adolescents (e.g., Andershed et al. 2002a, b; Dolan and Rennie 2006a) and is associated with criminal or antisocial behavior (e.g., Declercq et al. 2009; Dolan and Rennie 2006a, b, 2007; Larsson et al. 2006; Poythress et al. 2006; Salekin et al. 2010; Skeem and Cauffman 2003) and drug and alcohol use (e.g., Hillege et al. 2010; Poythress et al. 2006). The validity of the YPI has further been demonstrated by significant moderate to moderate-high correlations in samples of boys and girls with the PCL: YV ( $r=0.29-0.51$; Andershed et al. 2007; Dolan and Rennie 2006b; Chauhan et al. 2012; Skeem and Cauffman $2003)$ and even higher with the APSD $(r=0.76-0.77$; Seals et al. 2012; Poythress et al. 2006).

A shortened version of the YPI was recently developed in order to reduce administration time. The Youth Psychopathic traits Inventory - Short version (YPI-S; Van Baardewijk et al. 2010) is a brief 18-item version of the YPI developed through a stepwise selection process using a series of exploratory and confirmatory factor analyses, and content related arguments. It is organized in three factors, without the subscales composing the original YPI that are supposed to capture the same interpersonal, affective, and behavioral traits of the psychopathy construct. According to Colins et al. (2012), the YPI-S, by not including subscales, may have solved a concern that relates to an inappropriate use of parceling (using subscale scores rather than raw items) in factor analyses, namely not justifying the assumption of unidimensionality.

The only two YPI-S studies published to date (Colins et al. 2012; Van Baardewijk et al. 2010), both use participants from community samples, revealed the expected threefactor structure, namely: the Grandiose-Manipulative (Interpersonal), the Callous-Unemotional (Affective), and the Impulsive-Irresponsible (Behavioral) dimensions. However, Colins et al. (2012) found that one item (i.e., "I have probably skipped school or work more than most other people") showed a low standardized loading of 0.11 , but decided to retain it in order to test whether the original YPI-S factor structure could be replicated. The internal consistencies measured by Cronbach's alpha of the YPI-S total and its three dimensions were generally modest to good: the YPI-S total ranging from 0.78 to 0.85 , the Grandiose-Manipulative dimension from 0.76 to 0.81 , the Callous-Unemotional dimension from 0.66 to 0.75 , and the Impulsive-Irresponsible from 0.66 to 0.68 .

The YPI-S showed high convergence with the original YPI, and the two shared similar correlations to external criterion measures (Van Baardewijk et al. 2010). Additionally, youth with high scores on all three dimensions showed more 
conduct problems and committed more offenses than those with low scores (Colins et al. 2012). Positive and statistically significant associations with externalizing problems, conduct problems, peers problems, and diverse types of offending were also found. Unfortunately, the psychometric properties of the YPI-S have yet to be examined using clinic-referred or forensic (i.e., justice involved juveniles) samples, and there is still no data on the convergent validity of the YPI-S with other psychopathy measures (e.g., APSD), on the concurrent validity with psychiatric diagnostics (e.g., DSM-5's Conduct Disorder), or on criterion-related criminal variables (e.g., crime seriousness).

The literature regarding juvenile psychopathy has largely centered on the debate about the utility and stability of the North American construct of psychopathy, overlooking measurement and construct validity among non-North-American subjects (Dolan and Rennie 2006a, b). Because the expression of personality characteristics could vary across ethnic groups, it is crucial to examine the cross-ethnic generalizability of the YPI (Cooke et al. 2004; Veen et al. 2011). The main aim of the present study is to examine the psychometric properties of the YPI and of the YPI-S among a forensic sample of incarcerated Portuguese juvenile delinquents. To our knowledge this is the first study attempting to investigate the psychometric properties of both the YPI and of the YPI-S among incarcerated juvenile delinquents. Consistent with prior research we hypothesized that a tridimensional factor structure would be identified for both instruments among the current forensic sample. Next, several external criteria were included in the current study to test the convergent and discriminant validity of the YPI and YPI-S. Based on prior research, it was hypothesized that both measures would show convergent validity with existing measures of psychopathy (e.g., APSD) and discriminant validity with a social anxiety measure. It was also expected that the YPI and the YPI-S scores would be significantly associated with conduct disorder, age of crime onset, increased crime severity, use of physical violence, alcohol abuse, drug use, and risky sexual behavior.

\section{Method}

\section{Participants}

Male inmates from the eight nation-wide juvenile detention centers managed by the Portuguese Ministry of Justice voluntarily agreed to participate in the current study $(N=221)$. They were all detained by the court's decision. Incarceration into juvenile detention centers is the hardest measure a Portuguese court can decide. Seven of the detention centers are considered low to medium security, and one is considered maximum security (exclusively used for youths tried as adults).
The participants (mean age $=16.75$ years; $S D=1.41$ years; age range $=13-20$ years) were white Europeans $(54.3 \%)$, black Africans $(20.5 \%)$, mixed race South-Americans $(18.6 \%)$, and members of other ethnic minorities $(6.8 \%)$. Most of the participants came from an urban background $(92.8 \%)$. Their first criminal problems had been early in their lives (mean $=11.33$ years, $S D=2.24$ years), most were detained before they were 16 years old (mean $=15.46$ years, $S D=1.31$ years), and had been convicted to an average of 21 months in detention (mean=20.67 months, $S D=$ 6.69 months). Most of them (87.6\%) were convicted of having committed serious and/or violent crimes (e.g., homicide, robbery, assault, rape).

\section{Measures}

The Youth Psychopathic Traits Inventory (YPI; Andershed et al. 2002a, b) is a 50-item self-report measure designed to assess the core personality traits of the psychopathic personality constellation in youth aged 12 years old and up. Each item is scored on an ordinal 4-point Likert scale ranging from "Does not apply at all" to "Applies very well". The YPI consists of 10 subscales (with 5 items each) designed in line with Cooke and Michie's (2001) three-dimensional conceptualization of the psychopathy construct, namely: the GrandioseManipulative dimension, the Callous-Unemotional dimension, and the Impulsive-Irresponsible dimension. More specifically, the Grandiose-Manipulative dimension consists of the Dishonest charm, Grandiosity, Lying, and Manipulation subscales; the Callous-Unemotional dimension consists of the Callousness, Unemotionality, and Remorselessness subscales; the Impulsive-Irresponsible dimension consists of the Impulsivity, Thrill-seeking, and Irresponsibility subscales. Higher scores reflect an increased presence of the characteristics associated, namely psychopathic traits.

The Youth Psychopathic Traits Inventory-Short (YPI-S; Van Baardewijk et al. 2010) is an 18-item self-report shorter version of the original YPI (Andershed et al. 2002a, b) designed to measure psychopathic-like traits in adolescents. All the items of the YPI-S came from the original YPI. Stepwise parallel reduction using principal components analysis and content-related arguments were used to develop the YPI-S. A three-factor structure almost identical to the factor structure of the YPI (see above) was demonstrated in boys and girls. The YPI-S showed strong convergence with the original YPI and similar correlations to external criterion. Each item in the YPI-S is scored on a 4 point Likert scale ranging from "Does not apply at all" to "Applies very well". The YPI can be scored by simply adding the items. Higher scores indicate an increased presence of the characteristics associated.

The APSD-Self-Report (APSD-SR; Frick and Hare 2001; Caputo et al. 1999) is a multidimensional 20-item measure designed to assess psychopathic traits in adolescents. It was 
modeled after the PCL-Revised (PCL-R; Hare 2003). Each item is scored on a 3-point ordinal scale ranging from "Never" to "Often". The total score, as well as each dimension score, is obtained by adding the respective items. Some studies (e.g., Frick et al. 1994) reported two main factors (Callous-Unemotional and Impulsivity/Conduct problems), while others (e.g., Frick et al. 2000) reported three main factors: Callous-Unemotional, Narcissism and Impulsivity. Higher scores indicate higher psychopathic traits. The Portuguese validation of the APSD-SR (Pechorro et al. 2013) was used. The internal consistency for the current study, estimated by Cronbach's alpha, was: APSD-SR total $=0.81$; APSD-SR Callous-Unemotional dimension $=0.68$; APSD-SR Impulsivity dimension $=0.60$; APSD-SR Narcissism dimension $=0.74$.

The Inventory of Callous-Unemotional Traits (ICU; Essau et al. 2006; Kimonis et al. 2008) is a 24-item self-report scale designed to assess callous and unemotional traits in youth derived from the callous-unemotional (CU) subscale of the Antisocial Process Screening Device (APSD; Frick and Hare 2001). Each item is scored on a four-point scale ranging from "Not at all true" to "Definitely true". Scores are calculated by reverse-scoring the positively worded items and then summing the items to obtain a total score. Using confirmatory factor analysis it was possible to identify three independent factors, namely: Callousness, Unemotional, and Uncaring. All items also loaded onto a general callous-unemotional factor. Higher scores indicate an increased presence of $\mathrm{CU}$ traits. The Portuguese validation of the ICU (Pechorro et al. 2015) was used. The internal consistency for the current study, estimated by Cronbach's alpha, was: ICU total $=0.90$; ICU Callousness dimension $=0.88$; ICU Uncaring dimension $=0.86$; ICU Unemotional dimension $=0.87$.

The Social Anxiety Scale for Adolescents (SAS-A; La Greca and Lopez 1998) is an 18-item self-report scale designed to assess subjective experience of social anxiety in adolescents. Each item is rated on a five-point scale ranging from "Not at all" to "All the time". Three distinct subscales have been identified: the Fear of Negative Evaluation (FNE) subscale has eight items and reflects fears, concerns, or worries regarding negative evaluations from peers; the Social Avoidance and Distress - New (SAD-New) subscale has six items and reflects social avoidance and distress with new social situations or unfamiliar peers; the Social Avoidance and Distress - General (SAD-General) subscale has four items and reflects more generalized or pervasive social distress, discomfort, and inhibition. Scores are obtained by summing the ratings for the items comprising each subscale. The Portuguese validation of the SAS-S (Pechorro et al. 2014b) was used. Internal consistency for the present study, estimated by Cronbach's alpha, was: SAS-A total $=0.91$; SAS-A FNE dimension $=0.91$; SAS-A SAD-New dimension $=0.89$; SAS-A SAD-General dimension $=0.75$.
The Child and Adolescent Taxon Scale (CATS; Harris et al. 1994; Quinsey et al. 2006) is an actuarial rating scale developed from variables related to childhood and adolescent antisocial and psychopathic characteristics. Harris et al. (1994) established that eight childhood variables could identify members of the antisocial/psychopathic class. These variables include the following: (a) elementary school maladjustment, (b) teen alcohol abuse, (c) childhood aggression, (d) childhood behavior problems, (e) parental alcohol problems, (f) suspended or expelled from school, (g) separated from parents before age 16, and (h) arrested before age 16. The eight variables scored either 0 (No) or 1 (Yes), and summed to form a scale that ranges from 0 to 8 . Higher scores indicate an increased presence of the characteristics associated.

The Sellin-Wolfgang Index of Crime Seriousness (ICS; Wolfgang et al., as cited in White et al. 1994) guided the delinquency seriousness classification of the official court reports. Level 0 consists of no delinquency. Level 1 consists of minor delinquency committed at home such as stealing minor amounts of money from mother's purse. Level 2 consists of minor delinquency outside the home including shoplifting something worth less than 5 euros, vandalism and minor fraud (e.g. not paying bus fare). Level 3 consists of moderately serious delinquency such as any theft over 5 euros, gang fighting, carrying weapons, and joyriding. Level 4 consists of serious delinquency such as car theft and breaking and entering. Level 5 consists of having performed at least two of each of the behaviors in level 4 .

In addition, a questionnaire was constructed to describe the socio-demographic and criminal characteristics of the participants, to offer a descriptive account of the sample, and to explore the association of some of these variables (e.g., age of onset) with YPI scores. This questionnaire included variables such as participants' age, nationality, ethnic group, origin (rural vs. urban), level of schooling completed, age of crime onset, length of the conviction, use of physical violence in committing crimes, alcohol use, cannabis use, cocaine/ heroin use, and having unprotected sex (i.e., sex without using condoms). DSM-5's Conduct Disorder (CD; American Psychiatric Association 2013) was assessed using the official diagnostic criteria (i.e., the standard method described in the DSM-5).

\section{Procedures}

Authorization to validate the YPI and the YPI-S among Portuguese youth was obtained from the first author of the inventory (Andershed et al. 2002a, b). Appropriate procedures (e.g., avoiding item bias or differential item functioning) were followed during the translation and retroversion (Hambleton et al. 2005). The initial translation from English into Portuguese was completed by the first and last authors of this article, who made sure that young people would be able to 
properly understand the meaning of the items. The questionnaire was then independently translated back into English by a native English speaker with considerable professional experience in translating psychology-related scientific texts. No significant differences were found between the back-translation and the original version, demonstrating that the translated items had the same or very similar meanings as the original English items.

Authorization to assess youths was obtained from the General Directorate of Reintegration and Prison Services Ministry of Justice (Direção-Geral de Reinserção e Serviços Prisionais - Ministério da Justiça). The detainees, from the eight existing Portuguese Juvenile Detention Centers that admit male youths, were informed about the nature of the study and asked to voluntarily participate. The participation rate was approximately $92 \%$. Not all young people agreed or were able to participate; reasons for this included refusal to participate (5\%), inability to participate due to not understanding the Portuguese language ( $2 \%$ ) and inability to participate due to security issues $(1 \%)$. The measures were administered by means of individual face-to-face interviews in an appropriate setting. It was stressed that there were no right or wrong answers and that for each item the youth should consider what he generally thinks or feels. Institutional files were also used to complement the information obtained (e.g., prior criminal activity and detentions, psychiatric diagnosis). Some of the information (e.g., socio-demographic variables) was obtained from self-reports. The first author made the diagnosis of Conduct Disorder (American Psychiatric Association 2013), after interviewing each youth and taking into consideration the institutional files (which also included the official psychiatric and psychological assessments of each youth).

\section{Data-Analytical Strategy}

The data was analyzed using SPSS v22 (IBM SPSS, 2013) and EQS 6.2 (Bentler and $\mathrm{Wu} 2008$ ). The factor structure of the Portuguese language version of the YPI was assessed with Confirmatory Factor Analysis (CFA) performed in EQS 6.2 (Bentler and Wu 2008; Byrne 2006), with the robust estimation methods. Goodness of fit indices were calculated, including chi-square/degrees of freedom or Satorra-Bentler chisquare/degrees of freedom, comparative fit index (CFI), incremental fit index (IFI), and root mean square error of approximation (RMSEA). A chi-square/degrees of freedom value $\leq 5$ is considered acceptable, a value $\leq 2$ is considered good, and $=1$ very good (Maroco 2014; West et al. 2012). A $\mathrm{CFI} \geq 0.90$ and $\mathrm{RMSEA} \leq 0.10$ indicate adequate fit, whereas a $\mathrm{CFI} \geq 0.95$ and RMSEA $\leq 0.06$ indicate good model fit (Byrne 2006; West et al. 2012). The incremental fit index, also known as Bollen's IFI, is relatively insensitive to sample size; values that exceed 0.90 are regarded as acceptable and above 0.95 are regarded as good (Maroco 2014).
Regarding the YPI, the CFA was performed on the subscale scores, not on the items per se, the same methodology used by Andershed et al. (2002a, b), while for the YPI-S the CFA was performed on the original scale items. The minimum value considered for an adequate loading was a standardized loading above 0.30 . Our models were a 1 st order factorial models and covariance between factors were freely estimated. Modification indexes were also considered but did not provide any suggestion of model modification that would significantly improve the measurement model. Polychoric correlations were used to perform the CFAs on the ordinal items of the YPI-S because they provide more accurate estimates for the true correlations between ordinal items than Pearson correlations (Holgado-Tello et al. 2010). Pearson correlations were used to analyze associations between scale variables, Spearman correlations were used with ordinal variables, and point-biserial correlations were used to analyze associations between nominal dichotomous variables and scale variables (Leech et al. 2008). Correlations were considered low if below 0.20 , moderate if between 0.20 and 0.50 , and high if above 0.50 . Mean inter-item correlations were considered good if between 0.15 and 0.50 (Clark and Watson 1995). Corrected item-total correlations were considered satisfactory if above 0.20 (Nunnally and Bernstein 1994). Cronbach's alphas were considered good if above 0.70 (Cortina 1993).

\section{Results}

Our first step in examining the psychometric properties of the Portuguese version of the YPI and YPI-S was to attempt to replicate, by means of CFA, the tridimensional factor structures of these instruments. As seen in the Table 1, the three factor structure of both the YPI and the YPI-S fitted the data well.

Presented in Table 2 are the subscale loadings of the YPI and item loadings of the YPI-S for the three-factor model drawn for the CFAs. As seen in the table, all loadings were above 0.30 in the intended factor, with the exception of item 5

Table 1 Goodness of fit indexes for different factor models of the YPI and YPI-S using Maximum Likelihood with robust estimation methods

\begin{tabular}{lllll}
\hline & S-B $\chi^{2} / \mathrm{df}$ & IFI & CFI & $\begin{array}{l}\text { RMSEA } \\
(90 \% \mathrm{CI})\end{array}$ \\
\hline YPI 2-factor & 2.72 & 0.97 & 0.97 & $0.09(0.07,0.11)$ \\
YPI 3-factor & 1.43 & 0.99 & 0.99 & $0.04(0.00,0.07)$ \\
YPI-S 2-factor & 2.90 & 0.83 & 0.83 & $0.09(0.08,0.10)$ \\
YPI-S 3-factor & 1.71 & 0.94 & 0.94 & $0.06(0.04,0.07)$ \\
\hline
\end{tabular}

YPI Youth Psychopathic Traits Inventory; YPI-S YPI Short version; $\chi^{2}$ chi-square; $S-B \chi^{2}$ Satorra-Bentler chi-square; $d f$ degrees of freedom; IFI Incremental Fit Index; CFI Comparative Fit Index; RMSEA (90\% CI) Root Mean Square Error of Approximation ( $90 \%$ Confidence Interval) 
Table 2 YPI subscale loadings for the confirmatory three-factor structure and YPI-S item loadings for the confirmatory three-factor robust structure

\begin{tabular}{|c|c|c|c|}
\hline & Factor 1 & Factor 2 & Factor 3 \\
\hline \multicolumn{4}{|l|}{ YPI grandiose-manipulative dimension } \\
\hline YPI dishonest charm subscale & 0.87 & & \\
\hline YPI grandiosity subscale & 0.70 & & \\
\hline YPI lying subscale & 0.67 & & \\
\hline YPI manipulation subscale & 0.90 & & \\
\hline \multicolumn{4}{|l|}{ YPI callous-unemotional dimension } \\
\hline YPI callousness subscale & & 0.48 & \\
\hline YPI unemotionality subscale & & 0.66 & \\
\hline YPI remorselessness subscale & & 0.85 & \\
\hline \multicolumn{4}{|l|}{ YPI impulsive-irresponsible dimension } \\
\hline YPI impulsiveness subscale & & & 0.77 \\
\hline YPI thrill-seeking subscale & & & 0.83 \\
\hline YPI irresponsibility subscale & & & 0.66 \\
\hline \multicolumn{4}{|l|}{ YPI-S grandiose-manipulative (interpersonal) dimension } \\
\hline 14. I have the ability to con people by using my charm and smile. & 0.81 & & \\
\hline 15. I am good at getting people to believe me when I make something up. & 0.76 & & \\
\hline 19. I have talents that go far beyond other people's. & 0.39 & & \\
\hline 20. It's easy for me to manipulate people. & 0.69 & & \\
\hline 38. When I need to. I use my smile and my charm to use others. & 0.76 & & \\
\hline 41. I am destined to become a well-known important and influential person. & 0.39 & & \\
\hline \multicolumn{4}{|l|}{ YPI-S callous-unemotional (affective) dimension } \\
\hline 12. I think that crying is a sign of weakness, even if no one sees you. & & 0.48 & \\
\hline 17. When other people have problems it is often their own fault therefore one should not help them. & & 0.39 & \\
\hline 25. To be nervous and worried is a sign of weakness. & & 0.59 & \\
\hline 39. I don't understand how people can be touched enough to cry by watching things on TV or movie. & & 0.48 & \\
\hline 44. To feel guilty and remorseful about things you have done that have hurt other people is a sign of weakness. & & 0.62 & \\
\hline 45. I don't let my feelings affect me as much as other people's feelings seem to affect them. & & 0.49 & \\
\hline \multicolumn{4}{|l|}{ YPI-S impulsive-irresponsible (behavioral) dimension } \\
\hline 5. I have probably skipped school or work more than most other people. & & & 0.28 \\
\hline 9. I consider myself as a pretty impulsive person. & & & 0.65 \\
\hline 18. It often happens that I talk first and think later. & & & 0.70 \\
\hline 29. I get bored quickly by doing the same thing over and over. & & & 0.42 \\
\hline 32. It often happens that I do things without thinking ahead. & & & 0.74 \\
\hline 34. It has happened several times that I've borrowed something and then lost it. & & & 0.41 \\
\hline
\end{tabular}

YPI Youth Psychopathic Traits Inventory; YPI-S YPI Short version

of the YPI-S, even though this item was still statistically significant.

The next step was the estimation of internal consistency reliability statistics in the form of Cronbach's alpha, mean inter-item correlations and corrected item-total correlation range for the YPI and the YPI-S. The results are presented in Table 3 and shows that the majority of the subscales and factors exhibited good to excellent internal consistency. Only the YPI Callousness subscale, YPI Unemotionality subscale, YPI Remorselessness subscale, YPI Irresponsibility subscale, and the YPI-S Affective dimension were below 0.70. The YPI
Callousness subscale and the YPI Unemotionality subscale exhibited Cronbach's alpha values below 0.60 .

Presented in Table 4 are the correlations between the YPI-S (total and its dimensions) and the original YPI (total and its dimensions). As seen in the table, these correlations were, as expected, moderate to high.

Correlations between the factors and total scores of the YPI and YPI-S and convergent validity variables are presented in Table 5. As shown in the table, the YPI total (and its dimensions) and of the YPI-S total (and its dimensions) with the APSD-SR, the ICU, and the CATS revealed moderate to high 
Table 3 Cronbach's Alpha, mean inter-item/subscale correlation, and corrected item/subscale-total correlation range for the YPI and the YPI-S

\begin{tabular}{llll}
\hline & Cronbach $\alpha$ & MI-I/SC & CI/S-TCR \\
\hline YPI total scale & 0.87 & 0.41 & $0.38-0.75$ \\
YPI G-M dimension & 0.86 & 0.61 & $0.63-0.80$ \\
YPI dishonest charm subscale & 0.85 & 0.52 & $0.44-0.77$ \\
YPI grandiosity subscale & 0.70 & 0.33 & $0.30-0.56$ \\
YPI lying subscale & 0.83 & 0.49 & $0.53-0.69$ \\
YPI manipulation subscale & 0.87 & 0.56 & $0.65-0.75$ \\
YPI C-U dimension & 0.70 & 0.43 & $0.43-0.60$ \\
YPI callousness subscale & 0.59 & 0.23 & $0.21-0.51$ \\
YPI unemotionality subscale & 0.58 & 0.22 & $0.22-0.36$ \\
YPI remorselessness subscale & 0.67 & 0.28 & $0.28-0.44$ \\
YPI I-I dimension & 0.79 & 0.56 & $0.58-0.68$ \\
YPI impulsiveness subscale & 0.75 & 0.37 & $0.36-0.60$ \\
YPI thrill-seeking subscale & 0.73 & 0.36 & $0.42-0.58$ \\
YPI irresponsibility subscale & 0.68 & 0.29 & $0.28-0.52$ \\
YPI-S total scale & 0.82 & 0.21 & $0.19-0.58$ \\
YPI-S interpersonal dimension & 0.80 & 0.40 & $0.37-0.68$ \\
YPI-S affective dimension & 0.67 & 0.25 & $0.30-0.50$ \\
YPI-S behavioral dimension & 0.70 & 0.28 & $0.23-0.55$ \\
\hline
\end{tabular}

YPI Youth Psychopathic Traits Inventory; YPI-S YPI Short version; Cronbach $\alpha$ Cronbach's alpha; MI-I/SC mean inter-item/subscale correlation; $C I / S-T C R$ corrected item/subscale-total correlation range

statistically significant positive correlations, while the discriminant validity with the SAS-A revealed mostly the expected low non-significant correlations. The correlations with DSM5's Conduct Disorder diagnostic (coded No $=0$, Yes $=1$ ), age of crime onset, crime seriousness, and use of physical violence (coded $\mathrm{No}=0$, Yes $=1$ ) revealed mostly moderate statistically significant correlations. Regarding DSM-5's CD diagnostic, a very high prevalence rate of $94.1 \%$ was found in the present sample. The correlations with alcohol use, cannabis use, cocaine/heroin use, and having unprotected sex (coded as five-point ordinal scales) revealed mostly moderate and moderate-low statistically significant correlations; the exception was the unprotected sex (i.e., sex without using condoms) variable which was always non-significant with the YPI-S (see Table 5).

\section{Discussion}

The present study aimed to test the psychometric properties of the YPI and the YPI-S among incarcerated male juvenile delinquents. The issue of factor structure is important due to the ongoing debate of how best to define and measure psychopathy. Evidence obtained in our study shows that the three-factor model is the most acceptable one for the Portuguese version of the YPI, whereas a two-factor model did not fit the data well. Other studies (e.g., Andershed et al. 2002a, 2007, b; Van Baardewijk et al. 2010) have found supporting evidences for the three-dimensional nature of psychopathy in youths and it does seems to also apply in the current sample of incarcerated Portuguese adolescents. Regarding the YPI-S, the present study confirms that the three-factor model is applicable. Colins et al. (2012) and Van Baardewijk et al. (2010) have also found supporting evidence for the three-dimensional structure of the YPI-S in community youths, which thus also seems to be the case in the current incarcerated sample. However, one item, namely "I have probably skipped school or work more than most other people", showed a low standardized loading but was still statistically significant. Because this loading was very close to the minimum value considered an adequate loading, we decided to keep it. Colins et al. (2012) found a similar problem with this item in their community sample, indicating that it may need to be revised.

The Pearson correlations between the YPI total with its dimensions showed mostly moderate to high statistically significant positive associations. The same pattern of associations was observable regarding the original YPI-S and
Table 4 Correlations matrix between YPI-S and YPI factors and totals

\begin{tabular}{lllllllll}
\hline & YPI-S & YPI-S I & YPI-S A & YPI-S B & YPI & YPI G-M & YPI C-U & YPI I-I \\
\hline YPI-S & 1 & & & & & & \\
YPI-S I & $0.84^{* * *}$ & 1 & & & & & \\
YPI-S A & $0.78^{* * *}$ & $0.55^{* * *}$ & 1 & & & & \\
YPI-S B & $0.69^{* * *}$ & $0.36^{* * *}$ & $0.25^{* * *}$ & 1 & & & \\
YPI & $0.92^{* * *}$ & $0.84^{* * *}$ & $0.65^{* * *}$ & $0.64^{* * *}$ & 1 & & \\
YPI G-M & $0.83^{* * *}$ & $0.92^{* * *}$ & $0.57^{* * *}$ & $0.40^{* * *}$ & $0.90^{* * *}$ & 1 & \\
YPI C-U & $0.77^{* * *}$ & $0.60^{* * *}$ & $0.81^{* * *}$ & $0.36^{* * *}$ & $0.82^{* * *}$ & $0.64^{* * *}$ & 1 & \\
YPI I-I & $0.69^{* * *}$ & $0.46^{* * *}$ & $0.27^{* * *}$ & $0.88^{* * *}$ & $0.76^{* * *}$ & $0.48^{* * *}$ & $0.48^{* * *}$ & 1 \\
\hline
\end{tabular}

YPI Youth Psychopathic Traits Inventory; YPI-S YPI Short version; YPI-S I Interpersonal dimension; YPI-S A Affective dimension; YPI-S B Behavioral dimension; YPI G-M Grandiose-Manipulative dimension; $Y P I C-U$ Callous-Unemotional dimension; YPI I-I Impulsive-Irresponsible dimension

$* * *$ Significant at the 0.001 level 
Table 5 Correlations of YPI / YPI-S and its dimensions with other variables

\begin{tabular}{|c|c|c|c|c|}
\hline & YPI total / YPI-S total & YPI G-M / YPI-S I & YPI C-U / YPI-S A & YPI I-I / YPI-S B \\
\hline APSD-SR & $0.64 * * * / 0.54 * * *$ & $0.57 * * * / 0.52 * * *$ & $0.46 * * * / 0.27 * * *$ & $0.55^{* * *} / 0.45^{* * *}$ \\
\hline ICU & $0.49 * * * / 0.37 * * *$ & $0.30 * * * / 0.25 * * *$ & $0.52 * * * / 0.26 * * *$ & $0.47 * * * / 0.36 * * *$ \\
\hline CATS & $0.32 * * * / 0.26 * * *$ & $0.20 * * / 0.20 * *$ & $0.19^{* *} / 0.08^{\mathrm{ns}}$ & $0.44 * * * / 0.32 * * *$ \\
\hline SAS-A & $0.13^{n s} / 0.13^{n s}$ & $0.12^{n s} / 0.13^{n s}$ & $-0.08^{n s} / 0.00^{n s}$ & $0.13^{n s} / 0.14^{n s}$ \\
\hline DSM-5 CD & $0.25 * * * / 0.23 * *$ & $0.15 * / 0.17 *$ & $0.17 * * / 0.08^{n s}$ & $0.34 * * * / 0.29 * * *$ \\
\hline $\mathrm{ACO}$ & $-0.26^{* * *} /-0.22 * *$ & $-0.18 * * /-0.17 *$ & $-0.23 * * /-0.13^{n s}$ & $-0.26 * * * /-0.20 * *$ \\
\hline ICS & $0.26^{* * *} / 0.21^{* *}$ & $0.13^{n s} / 0.13^{n s}$ & $0.19^{* *} / 0.10^{n s}$ & $0.36^{* * *} / 0.26^{* * *}$ \\
\hline UPV & $0.16^{*} / 0.15^{*}$ & $0.04^{n s} / 0.08^{n s}$ & $0.15^{*} / 0.07^{n s}$ & $0.26^{* * *} / 0.20^{* *}$ \\
\hline Alcohol & $0.29 * * * / 0.23 * *$ & $0.17 * / 0.18^{* *}$ & $0.22 * * / 0.09^{n s}$ & $0.33^{* * *} / 0.26^{* * *}$ \\
\hline Cannabis & $0.37 * * * / 0.27 * * *$ & $0.20 * * / 0.19 * *$ & $0.32 * * * / 0.15 *$ & $0.43 * * * / 0.31 * * *$ \\
\hline Cocaine/heroin & $0.28 * * * / 0.28 * * *$ & $0.23 * * / 0.21 * *$ & $0.18^{* *} / 0.11^{n s}$ & $0.28 * * * / 0.30 * * *$ \\
\hline Unprotected sex & $0.15^{*} / 0.13^{n s}$ & $0.07^{n s} / 0.12^{n s}$ & $0.13^{n s} / 0.04^{n s}$ & $0.17 * / 0.09^{n s}$ \\
\hline
\end{tabular}

YPI Youth Psychopathic Traits Inventory; YPI G-M Grandiose-Manipulative dimension; YPI C-U Callous-Unemotional dimension; YPI I-I ImpulsiveIrresponsible dimension; YPI-S YPI Short version; YPI-S I Interpersonal dimension; YPI-S A Affective dimension; YPI-S B Behavioral dimension; APSD-SR Antisocial Process Screening Device - Self-Report; ICU Inventory of Callous-Unemotional Traits; CATS Child and Adolescent Taxon Scale; $S A S-A$ Social Anxiety Scale - Adolescent; DSM-5 CD DSM-5 Conduct Disorder diagnosis; ACO Age of crime onset; ICS Index of Crime Seriousness; $U P V$ Use of physical violence

***Significant at the 0.001 level; **Significant at the 0.01 level; *Significant at the 0.05 level; $n s$ non-significant

its dimensions, and regarding the correlations between YPI-S (and its dimensions) and the original YPI (and its dimensions). These values were similar to the ones found by other authors (Colins et al. 2012; Van Baardewijk et al. 2010).

Some psychometric problems were found. Analyses of the internal consistency of the YPI revealed somewhat low values especially for the Unemotionality subscale and the Callousness subscale, and also for the Remorselessness subscale and the Irresponsibility subscale. Thus, this questions the reliability of these scales, since only a small portion of the variance is attributable to them (Cortina 1993; Kaplan and Saccuzzo 2009). However, these values are not exclusive to our study (e.g., Chauhan et al. 2012; Declercq et al. 2009) and thus may be more general issues of the YPI rather than linked to the Portuguese translation or sample. Thus, it may well be the case that some items of these subscales and dimensions need to be revised. In particular, the only items of the YPI that are reversed (no reversed items are included in the YPI-S), generally show quite low inter-item correlations, which was also the case in the present sample (shown by complementary analyses - not shown in tables). Thus, future studies should examine whether not reverse coding items may improve the reliability of YPI subscales that underperformed. The YPI total, the three dimensions and rest of the subscales presented good or very good values (Cronbach's alpha $=0.70-0.87$ ). Regarding the YPI-S, the analysis of the internal consistency revealed a somewhat low value (i.e., 0.67) for the Affective dimension questioning the reliability of measurements for this dimension (Cortina 1993; Kaplan and Saccuzzo 2009), but the
YPI-S total and the remaining dimensions presented good values. Similar findings have been found in previous studies (e.g., Colins et al. 2012) and are not easy to explain. It is worth pointing out that the Affective dimension of the YPI-S does not include any reversed items.

In terms of the mean inter-item correlations of the YPI, no problems were found because the total scale, the three dimensions and the subscales all reached a minimum 0.15 mean inter-item correlation (Clark and Watson 1995; Domino and Domino 2006). However, the mean inter-item correlations for the Dishonest charm subscale, Manipulation subscale, Grandiose-Manipulative dimension, and ImpulsiveIrresponsible dimension were above the maximum recommended value of 0.50 , indicating that there might be some excessive homogeneity present. The corrected item/subscaletotal correlation range of the YPI total, of the three dimensions and of the subscales were all above the minimum recommended value of 0.20 (Kaplan and Saccuzzo 2009; Nunnally and Bernstein 1994). Regarding the YPI-S, the mean inter-item correlations revealed no problems. That is, YPI-S total and its three dimensions were all within the recommended value range of 0.15-0.50 (Clark and Watson 1995; Domino and Domino 2006), showing adequate homogeneity between the items. In terms of the corrected item-total correlation range, the three dimensions of the YPI-S were all above the minimum recommended value of 0.20 (Kaplan and Saccuzzo 2009; Nunnally and Bernstein 1994), but the YPI-S total did not reach that value although it was very close.

The convergent validity of the YPI and its dimensions with the APSD-SR, the ICU and the CATS revealed mostly 
moderate-high statistically significant correlations demonstrating the expected overlap in line with previous studies (e.g., Seals et al. 2012; Poythress et al. 2006), while the discriminant validity with the SAS-A revealed mostly the expected null correlations (American Psychological Association 1999; Kaplan and Saccuzzo 2009). The concurrent validity of the YPI and its dimensions with DSM's Conduct Disorder (American Psychiatric Association 2013) showed moderate associations that were somewhat lower than the typical correlation range provided by youth psychopathy instruments (e.g., Forth et al. 2003; Pechorro et al. 2013) but still statistically significant; the exception was the GrandioseManipulative dimension with a lower correlation. Regarding the YPI-S, basically the same pattern of correlations emerged, but these were somewhat lower. The very high prevalence rate of conduct disorder in the current sample $(94.1 \%)$ was higher than what is typical of some forensic samples (Sevecke and Kosson 2010).

The correlations of the YPI and its dimensions with the criminal variables revealed mostly the existence of moderate-low negative associations with age of crime onset, and the existence of moderate-low positive associations with crime seriousness and the use of physical violence when committing crimes, with the exceptions of the Grandiose-Manipulative dimension which revealed mostly non-significant correlations. Regarding the YPI-S, basically the same pattern of correlations emerged, but these were somewhat lower. Negative associations between psychopathy scores and the age of crime onset have been consistently reported in the literature (e.g., Forth et al. 2003; Pechorro et al. 2014a, b), although the one we obtained was somewhat lower but still statistically significant. Positive associations between psychopathy scores and antisocial and criminal behavior variables similar to the ones we obtained have been consistently reported in the literature (e.g., Dolan and Rennie 2006a, b, 2007; Larsson et al. 2006; Poythress et al. 2006; Salekin et al. 2010; Skeem and Cauffman 2003).

As expected, the positive correlations of the YPI (and its dimensions) and of the YPI-S (and its dimensions) with alcohol use, cannabis use, and cocaine/heroin were mostly moderate to low (e.g., Colins et al. 2012); the exception was the Affective dimension of the YPI-S which revealed a non-significant association with cocaine/heroin use. Statistically significant associations were found regarding the unprotected sex variable, although smaller in strength than previously reported (e.g., Rucevic 2010). The exceptions were the Grandiose-Manipulative dimension and the Callous-Unemotional dimension of the YPI which revealed non-significant correlations, while regarding the YPI-S no significant associations were found. Overall, the YPI-S presented somewhat weaker relations to external correlates, but less problems with reliability.
Our findings provide some additional support for the extension of the psychopathy construct to adolescents and its potential generalization across different cultures and ethnic groups. We were able to demonstrate some appropriate psychometric properties that justify the future use of the YPI and the YPI-S. However, some caution is advised since the Portuguese validation of these important instruments is still ongoing. Further psychometric procedures are needed and should be done in the near future (e.g., cross-validation using other samples, discriminant validity, test-retest reliability, known-groups validity). Another serious limitation was the relatively small sample size, which is an important issue given that CFA was used (both Type I and II errors are much more likely with small samples, and this concern is elevated when the data are skewed).

To our knowledge this is the first study attempting to investigate the psychometric properties of both the YPI and of the YPI-S among incarcerated male juvenile delinquents. Considering the enormous costs that persons with psychopathic traits create in terms of their crimes and collateral effects on victims and society as a whole, we hope that our study may guide future research/use of these instruments with Portuguese youth, promote research of the psychopathy construct in southern European countries, contribute to the betterment of treatment programs of serious and violent juvenile offenders in Portugal, and promote future research and a more generalized use of the YPI-S. In conclusion, the present study generally lends support to the criterion, external, and divergent validity of both the YPI and YPI-S among incarcerated males. The correlations to external validity correlates of the YPI are however generally somewhat stronger than those of the YPI-S. Another important conclusion is that the affective part of both the YPI and YPI-S exhibit relatively low internal consistency reliability underlining the need for further development of the YPI and YPI-S.

Acknowledgments This research was supported by the Portuguese Foundation for Science and Technology (FCT) with co-financing of the European Social Fund - POPH/FSE (Grant SFRH/BPD/86666/2012).

We wish to thank the following Portuguese juvenile detention centers for their collaboration: Bela Vista, Mondego, Navarro de Paiva, Olivais, Padre António Oliveira, Santo António, Santa Clara, Prisão-Escola de Leiria.

Conflict of Interest Pedro Pechorro, Henrik Andershed, James V. Ray, João Maroco, and Rui Abrunhosa Gonçalves declare that they have no conflict of interest.

Experiment Participants Informed Consent were followed.

\section{References}

American Psychiatric Association. (2013). Diagnostic and statistical manual of mental disorders (5th ed.). Washington, DC: Author. 
American Psychological Association. (1999). Standards for educational and psychological tests. Washington, DC: Author.

Andershed, H., Kerr, M., Stattin, H., \& Levander, S. (2002a). Psychopathic traits in non-referred youths: Initial test of a new assessment tool. In E. Blaauw \& L. Sheridan (Eds.), Psychopaths: Current international perspectives (pp. 131-158). Haag: Elsevier.

Andershed, H., Gustafson, S., Kerr, M., \& Stattin, H. (2002b). The usefulness of self-reported psychopathy-like traits in the study of antisocial behavior among non-referred adolescents. European Journal of Personality, 16, 383-402.

Andershed, H., Hodgins, S., \& Tengstrom, A. (2007). Convergent validity of the Youth Psychopathic traits Inventory (YPI). Assessment, 14, 144-154.

Bentler, P., \& Wu, E. (2008). EQS for Windows user's guide. Encino: Multivariate Software, Inc.

Brandt, J., Kennedy, W., Patrick, C., \& Curtin, J. (1997). Assessment of psychopathy in a population of incarcerated adolescent offenders. Psychological Assessment, 9, 429-435.

Byrne, B. (2006). Structural equation modeling with EQS: Basic concepts, applications, and programming. Mahwah: Lawrence Erlbaum Associates.

Caputo, A., Frick, P., \& Brodsky, S. (1999). Family violence and juvenile sex offending. Criminal Justice and Behavior, 26, 338-356.

Cauffman, E., Kimonis, E., Dmitrieva, J., \& Monahan, K. (2009). A multimethod assessment of juvenile psychopathy: Comparing the predictive utility of the PCL:YV, YPI, and NEO PRI. Psychological Assessment, 21(4), 528-542.

Chauhan, P., Ragbeer, S., Burnette, M., Oudekerke, B., Reppucci, N., \& Moretti, M. (2012). Comparing the Youth Psychopathic Traits Inventory (YPI) and the Psychopathy Checklist-Youth Version (PCL-YV) among offending girls. Assessment, 21(2), 181-194.

Clark, L., \& Watson, D. (1995). Constructing validity: basic issues in objective scale development. Psychological Assessment, 7(3), 309-319.

Cleckley, H. (1976). The mask of sanity (5th ed.). St Louis: Mosby.

Colins, O., Noom, M., \& Vanderplasschen, W. (2012). Youth Psychopathic Traits Inventory - Short version: a further test of the internal consistency and criterion validity. Journal of Psychopathology and Behavioral Assessment, 34, 476-486.

Cooke, D., \& Michie, C. (2001). Refining the construct of psychopathy: towards a hierarchical model. Psychological Assessment, 13, 171-188.

Cooke, D., Michie, C., Hart, S., \& Clark, D. (2004). Reconstructing psychopathy: clarifying the significance of antisocial and socially deviant behavior in the diagnosis of psychopathic personality disorder. Journal of Personality Disorders, 18, 337-357.

Cortina, J. (1993). What is coefficient alpha? An examination of theory and applications. Journal of Applied Psychology, 78(1), 98-104.

Declercq, F., Markey, S., Vandist, K., \& Verhaeghe, P. (2009). The Youth Psychopathic Trait Inventory: factor structure and antisocial behaviour in non-referred 12-17-year-olds. Journal of Forensic Psychiatry and Psychology, 20(4), 577-594.

Dolan, M., \& Rennie, C. (2006a). Reliability, validity, and factor structure of the Swedish Youth Psychopathic Trait Inventory in a UK sample of conduct disordered boys. The Journal of Forensic Psychiatry and Psychology, 17(2), 217-229.

Dolan, M., \& Rennie, C. (2006b). Psychopathy checklist: youth version and Youth Psychopathic trait Inventory: a comparison study. Personality and Individual Differences, 41(4), 779-789.

Dolan, M., \& Rennie, C. (2007). The relationship between psychopathic traits measured by the Youth Psychopathic Trait Inventory and psychopathology in a UK sample of conduct disordered boys. Journal of Adolescence, 30, 601-611.

Domino, G., \& Domino, M. (2006). Psychological testing: An introduction (2nd ed.). New York: Cambridge University Press.
Essau, C., Sasagawa, S., \& Frick, P. (2006). Callous-unemotional traits in community sample of adolescents. Assessment, 13, 454-469.

Falkenbach, D., Poythress, N., \& Heide, K. (2003). Psychopathic features in a juvenile diversion population: Reliability and predictive validity of two self-report measures. Behavioral Sciences and the Law, 21(6), 787-805.

Forth, A., Kosson, D., \& Hare, R. (2003). Hare Psychopathy Checklist: Youth Version (PCL:YV): Technical manual. Toronto: Multi-Health Systems.

Frick, P., Barry, C., \& Bodin, S. (2000). Applying the concept of psychopathy to children: Implications for the assessment of antisocial youth. In C. Gacono (Ed.), The clinical and forensic assessment of psychopathy: A practitioner's guide (pp. 1-24). Mahwah, NJ: Lawrence Erlbaum.

Frick, P., \& Hare, R. (2001). The Antisocial Process Screening Device (APSD): Technical manual. Toronto: Multi-Health Systems.

Frick, P., O’Brien, B., Wootton, J., \& McBurnett, K. (1994). Psychopathy and conduct problems in children. Journal of Abnormal Psychology, 103, 700-707.

Frick, P., Cornell, A., Barry, C., Bodin, S., \& Dane, H. (2003). Callousunemotional traits and conduct problems in the prediction of conduct problem severity, aggression, and self-report of delinquency. Journal of Abnormal Child Psychology, 3, 457-470.

Gretton, H., Hare, R., \& Catchpole, R. (2004). Psychopathy and offending from adolescence to adulthood: a 10-year follow-up. Journal of Consulting and Clinical Psychology, 72, 636-645.

Häkkänen-Nyholm, H., \& Nyholm, J.-O. (2012). Introduction. In H. Häkkänen-Nyholm \& J.-O. Nyholm (Eds.), Psychopathy and law: A practitioner's guide (pp. 1-16). Chichester: Wiley-Blackwell.

Hambleton, R., Merenda, P., \& Spielberger, C. (2005). Adapting educational and psychological tests for cross-cultural assessment. Mahwah: Lawrence Erlbaum Associates.

Hare, R. (1991). The hare psychopathy checklist-revised: Manual. Toronto: Multi-Health Systems.

Hare, R. (2003). Hare psychopathy checklist-revised (2nd ed.). Toronto: Multi-Health Systems.

Harris, G. T., Rice, M. E., \& Quinsey, V. L. (1994). Psychopathy as a taxon: evidence that psychopaths are a discrete class. Journal of Consulting and Clinical Psychology, 62, 387-397.

Hildebrand, M., de Ruiter, C., \& de Vogel, V. (2004). Psychopathy and sexual deviance in treated rapists: association with sexual and nonsexual recidivism. Sexual Abuse: A Journal of Research and Treatment, 16, 1-24.

Hillege, S., Das, J., \& Ruiter, C. (2010). The Youth Psychopathic traits Inventory: psychometric properties and its relation to substance use and interpersonal style in a Dutch sample of non-referred adolescents. Journal of Adolescence, 33, 83-91.

Holgado-Tello, F., Chacón-Moscoso, S., Barbero-García, I., \& VilaAbad, E. (2010). Polychoric versus Pearson correlations in exploratory and confirmatory factor analysis of ordinal variables. Quality \& Quantity, 44(1), 153-166.

IBM SPSS. (2013). IBM SPSS statistics base 22. Chicago: SPSS Inc.

Kaplan, R., \& Saccuzzo, D. (2009). Psychological testing: Principles, applications, and issues. Belmont: Wadsworth, Cengage Learning.

Kimonis, E., Frick, P., Skeem, J., Marsee, M., Cruise, K., Munoz, L., Aucoin, K., \& Morris, A. (2008). Assessing callous-unemotional traits in adolescent offenders: validation of the Inventory of CallousUnemotional Traits. Journal of the International Association of Psychiatry and Law, 31(3), 241-252.

Kotler, J., \& McMahon, R. (2005). Child psychopathy: theories, measurement, and relations with the development and persistence of conduct problems. Clinical Child and Family Psychology Review, $8,291-325$.

La Greca, A., \& Lopez, N. (1998). Social anxiety among adolescents: linkages with peer relations and friendships. Journal of Clinical Child Psychology, 26, 83-94. 
Larsson, H., Andershed, H., \& Lichtenstein, P. (2006). A genetic factor explains most of the variation in the psychopathic personality. Journal of Abnormal Psychology, 115, 221-230.

Leech, N., Barrett, K., \& Morgan, G. (2008). SPSS for intermediate statistics: Use and interpretation (3rd ed.). New York: LEA.

Leistico, A., Salekin, R., DeCoster, J., \& Rogers, R. (2008). A large scale meta-analysis relating the Hare measures of psychopathy to antisocial conduct. Law and Human Behavior, 32, 28-45.

Lindberg, N. (2012). Psychopathic features in adolescence. In H. Häkkänen-Nyholm \& J.-O. Nyholm (Eds.), Psychopathy and law: A practitioner's guide (pp. 127-138). Chichester: Wiley-Blackwell.

Maroco, J. (2014). Análise de Equações Estruturais: Fundamentos teóricos, software \& aplicações [Structural Equations Analysis: Theoretical foundations, software and applications]. Pero Pinheiro: ReportNumber.

Murrie, D., Cornell, D., Kaplan, S., McConville, D., \& Levy-Elkon, A. (2004). Psychopathy scores and violence among juvenile offenders: a multi-measure study. Behavioral Science \& Law, 22, 49-67.

Nunnally, J., \& Bernstein, I. (1994). Psychometric theory. New York: McGraw-Hill.

Pardini, D., \& Byrd, A. (2013). Developmental conceptualizations of psychopathic features. In K. Kiehl \& W. Sinnott-Armstrong (Eds.), Handbook on psychopathy and law (pp. 61-77). New York: Oxford University Press.

Pechorro, P., Maroco, J., Poiares, C., \& Vieira, R. (2013). Validation of the Portuguese version of the Antisocial Process Screening Device Self-Report with a focus on delinquent behavior and behavior problems. International Journal of Offender Therapy and Comparative Criminology, 57, 112-126.

Pechorro, P., Maroco, J., Gonçalves, R., Nunes, C., \& Jesus, S. (2014a). Psychopathic traits and age of crime onset in male juvenile delinquents. European Journal of Criminology, 11(3), 288-302.

Pechorro, P., Silva, I., Maroco, J., \& Gonçalves, R. (2014b). Propriedades psicométricas da Escala de Ansiedade Social para Adolescentes (SAS-A) em jovens institucionalizados [Psychometric properties of the Social Anxiety Scale for Adolescents (SAS-A) among institutionalized youth]. Psicologia, Saúde e Doenças, 15(3), 586-596.

Pechorro, P., Ray, J., Barroso, R., Maroco, J., \& Gonçalves, R. (2015). Validation of the inventory of callous-unemotional traits among Portuguese juvenile delinquents. International Journal of Offender Therapy and Comparative Criminology. doi:10.1177/ $0306624 X 14551256$

Poythress, N., Dembo, R., Wareham, J., \& Greenbaum, P. (2006). Construct validity of the Youth Psychopathic features Inventory (YPI) and the Antisocial Process Screening Device (APSD) with justice-involved adolescents. Criminal Justice and Behavior, 33(1), 26-55.

Quinsey, V., Harris, V., Rice, M., \& Cormier, C. (2006). Violent offenders: Appraising and managing risk (2nd ed.). Washington, DC: American Psychological Association

Rice, M., \& Harris, G. (2013). Psychopathy and violent recidivism. In K. Kiehl \& W. Sinnott-Armstrong (Eds.), Handbook on psychopathy and law (pp. 231-249). New York: Oxford University Press.

Rucevic, S. (2010). Psychopathic personality traits and delinquent and risky sexual behaviors in Croatian sample of non-referred boys and girls. Law and Human Behavior, 34, 379-391.

Salekin, R. (2010). Treatment of child and adolescent psychopathy: Focusing on change. In R. Salekin \& D. Lynam (Eds.), Handbook of child and adolescent psychopathy (p. 343373). New York: Guilford.

Salekin, R., \& Lynam, D. (2010). Child and adolescent psychopathy: An introduction. In R. Salekin \& D. Lynam (Eds.), Handbook of child and adolescent psychopathy (pp. 1-12). New York: Guilford.

Salekin, R. T., Debus, S. A., \& Barker, E. D. (2010). Adolescent psychopathy and the five factor model: Domain and facet analysis. Journal of Psychopathology and Behavioral Assessment, 32(4), 501-514.

Salekin, R., Neumann, C., Leistico, A., DiCicco, T., \& Duros, R. (2004). Psychopathy and comorbidity in a young offender sample: taking a closer look at psychopathy's potential importance over disruptive behavior disorders. Journal of Abnormal Psychology, 113, 416- 427.

Seals, R., Sharp, C., Ha, C., \& Michonski, J. (2012). The relationship between the Youth Psychopathic Traits Inventory and psychopathology in a U.S. community sample of male youth. Journal of Personality Assessment, 94(3), 232-243.

Sevecke, K., \& Kosson, D. (2010). Relationships of child and adolescent psychopathy to other forms of psychopathology. In R. Salekin \& D. Lynam (Eds.), Handbook of child and adolescent psychopathy (pp. 284-314). New York: The Guilford Press.

Skeem, J., \& Cauffman, E. (2003). Views of the downward extension: comparing the youth version of the psychopathy checklist with the youth psychopathic traits inventory. Behavioral Sciences and the Law, 21, 737-770.

Van Baardewijk, Y., Andershed, H., Stegge, H., Nilsson, K., Scholte, E., \& Vermeiren, R. (2010). Development and tests of short versions of the Youth Psychopathic Traits Inventory and the Youth Psychopathic Traits Inventory-Child Version. European Journal of Psychological Assessment, 26(2), 122-128.

Vaughn, M., \& Howard, M. (2005). The construct of psychopathy and its role in contributing to the study of serious, violent, and chronic youth offending. Youth Violence and Juvenile Justice, 3, 235-252.

Veen, V., Stevens, G., Andershed, H., Raaijmakers, Q., Doreleijers, T., \& Vollebergh, W. (2011). Cross-ethnic generalizability of the threefactor model of psychopathy: The Youth Psychopathic Traits Inventory in an incarcerated sample of native Dutch and Moroccan immigrant boys. International Journal of Law and Psychiatry, 34, 127-130.

Vitacco, M., \& Salekin, R. (2013). Adolescent psychopathy and the law. In K. Kiehl \& W. Sinnott-Armstrong (Eds.), Handbook on psychopathy and law (pp. 78-91). New York: Oxford University Press.

Vitacco, M., Caldwell, M., van Rybroek, G., \& Gabel, J. (2007). Psychopathy and behavioral correlates of victim injury in serious juvenile offenders. Aggressive Behavior, 33, 537-544.

Weizmann-Henelius, G., Putkonen, H., Grönroos, M., Lindberg, N., Eronen, E., \& Häkkänen-Nyholm, H. (2010). Examination of psychopathy in female homicide offenders - Confirmatory Factor Analysis of the PCL-R. International Journal of Law and Psychiatry, 33, 177-183.

West, S., Taylor, A., \& Wu, W. (2012). Model fit and model selection in structural equation modeling. In R. Hoyle (Ed.), Handbook of structural equation modeling (pp. 209-231). New York: The Guilford Press.

White, J., Moffitt, T., Caspi, A., Jeglum-Bartusch, D., Needles, D., \& Stouthamer-Loeber, M. (1994). Measuring impulsivity and examining its relation to delinquency. Journal of Abnormal Psychology, 103, 192-205. 